\title{
Helen Salisbury: The performance of kindness
}

\author{
Helen Salisbury GP \\ Oxford
}

Patients arrive at a GP appointment with all manner of symptoms and varying degrees of unease, anxiety, pain, and fear. If we aim for patients to leave feeling better than when they came, they need to know that they've been taken seriously and that their concerns have been explored and understood. They need to trust in the competence of the doctor and be able to rely on our kindness and empathy, even if practical solutions to their problems are in short supply.

Most of the time this isn't too hard-I have a cheerful disposition and enjoy my job, but I have off days like everyone, when I'm tired and feel burdened. It's not enough to rely on my genuine feelings of warmth and good will, because these are inevitably variable. They may peak when I'm rested and unhurried, but at the end of a long day, if my patients are not going to feel short changed by an uncaring doctor, I need to be intentionally kind. Even if I've just had the most difficult consultation, where the patient left unsatisfied and I'm now running half an hour late, it's my job not to show it. I must do my "housekeeping"- take a deep breath, relax my shoulders as I walk out to the waiting room, smile and greet the next patient, and apologise for the delay. ${ }^{1}$

Teaching students about expressing empathy sometimes brings the response, "I wouldn't want empathy if it wasn't genuine." However, if you practise and perform the actions that make it look as though you care-if you smile and listen, and if you're curious and empathetic_-does it matter what you really feel?
We need ingrained habits of consulting so that, no matter what our internal weather, our patients experience a caring doctor.

The distinction between genuine and performed kindness is an oversimplification, because they're not static and independent. To an extent, we become what we pretend to be. ${ }^{2}$ This happens in two ways-from the inside out and from the outside in. Our behaviour influences how we feel: if we make ourselves smile even when we're feeling grumpy, or if we're polite even when we're feeling cross, it's hard to hang on to those original moods. Acting in a kind way, saying kind words, alters how we feel. Even if it didn't, the experience for our patients is of someone being kind, and their responses to us reflect and reinforce this.

If it's your intention to be kind, and if you've practised the relevant skills, you may be having a bad day but your patients probably won't even notice. Don't beat yourself up about it—be kind to yourself too.

\section{Competing interests: See www.bmj.com/about-bmj/freelance-contributors.}

Provenance and peer review: Commissioned; not externally peer reviewed.

Neighbour R. The inner consultation: how to develop an effective and intuitive consulting style. 2nd ed. Routledge, 2004 (first published 1987).

2 Vonnegut K. Mother night. Vintage Classics, 1992 (first published 1962).

Published by the BMJ Publishing Group Limited. For permission to use (where not already granted under a licence) please go to http://group.bmj.com/group/rights-licensing/ permissions 